\title{
Tumor-suppressive function of UNC5D in papillary thyroid cancer
}

\author{
Man-Man Zhang ${ }^{1, *}$, Feng Sun ${ }^{1, *}$, Bing Cui ${ }^{2, *}$, Le-Le Zhang ${ }^{1}$, Ya Fang ${ }^{1}$, Yan Li ${ }^{1}$, Rui- \\ Jia Zhang ${ }^{1}$, Xiao-Ping Ye ${ }^{1}$, Yu-Ru Ma ${ }^{1}$, Bing Han ${ }^{1}$ and Huai-Dong Song ${ }^{1}$ \\ ${ }^{1}$ The Core Laboratory in Medicine Center of Clinical Research, Department of Endocrinology, Shanghai Ninth People's \\ Hospital, Shanghai Jiaotong University School of Medicine, Shanghai 200011, China \\ ${ }^{2}$ Department of Transfusion, The Hospital Affiliated to Jiangsu University, Zhenjiang 212001, China \\ *These authors should be regarded as joint first authors \\ Correspondence to: Huai-Dong Song, email: huaidong_s1966@163.com \\ Bing Han, email: foxhb1423@126.com \\ Keywords: UNC5D; papillary thyroid carcinoma; tumor-suppressive function; lymph node metastasis; BRAF mutation \\ Received: March 31, $2017 \quad$ Accepted: June 28, $2017 \quad$ Published: October 10, 2017 \\ Copyright: Zhang et al. This is an open-access article distributed under the terms of the Creative Commons Attribution License 3.0 \\ (CC BY 3.0), which permits unrestricted use, distribution, and reproduction in any medium, provided the original author and source \\ are credited.
}

\section{ABSTRACT}

Background: Studies have shown an association of the UNC5D gene with kidney and bladder cancer and neuroblastoma. We investigated whether UNC5D acts as a tumor suppressor in papillary thyroid carcinoma (PTC).

Methods: Primary PTC tumors and matched normal thyroid tissues were obtained from 112 patients to detect UNC5D mRNA by real-time PCR. Genomic DNA sequencing was performed to detect BRAF mutation in PTC tumors. The association between UNC5D expression and clinicopathological data from PTC patients was reviewed retrospectively. PTC-derived cancer cell lines TPC-1 and K1 with stable transfection of UNC5D were used to investigate the functions of UNC5D. Flow cytometry, CCK8, Transwell assay and scratch tests were used to examine cell cycle distribution, proliferation and migration.

Results: The expression of UNC5D was significantly decreased in PTC compared with adjacent normal thyroid tissues. Lower UNC5D expression was significantly associated with aggressive tumor behaviors, such as lymph node metastasis and BRAF mutation. Overexpression of UNC5D significantly suppressed malignant cell behaviors, including cell proliferation and migration, as well as tumor growth in vivo.

Conclusions: These findings suggest a potential tumor suppressor role of UNC5D in PTC progression; and provide insight into potential clinical relevance for the prognosis of PTC.

\section{INTRODUCTION}

Thyroid carcinoma, the most frequent primary malignancy in the endocrine organs, has experienced a rapidly increasing incidence and prevalence in recent decades [1]. Originating from thyroid follicular cells, papillary thyroid carcinoma (PTC) accounts for the vast majority of thyroid cancers $(80 \%)[2,3]$. PTC patients in early stages have a favorable prognosis, and the overall five-year survival rate is $95 \%$ [4]; however, when they occasionally de-differentiate into more aggressive and lethal thyroid cancers, the five-year survival rate drops to $59 \%$ in the late stage $[3,5]$. Clinical variables including advanced stage, extra-thyroidal tumor extension, lymph node metastasis (LNM), and distant metastases have been associated with a poor prognosis in PTC [6]. However, the potential molecular mechanisms underlying the aggressive behavior of some papillary carcinomas that result in recurrence and metastatic lesions remain poorly understood [7]. 
Recent studies using next-generation sequencing (NGS) have indicated that thyroid carcinoma is predominantly driven by genetic and epigenetic alterations [8]. Previous studies showed that a major class of driver genes of PTC is involved in the mitogen activated protein kinase (MAPK) signaling pathway, including point mutations in BRAF and Ras [9-12], as well as fusions involving the RET [13] and NTRK1 tyrosine kinases [14]. Mutations within the genes related in the phosphoinositide 3-kinase (PI3K) pathway, such as PTEN, PIK3CA, and $A K T 1$, have also been reported at low frequencies [8]. Recently, increasing numbers of tumor suppressor genes (TSGs) have been identified in PTC, which implies that TSGs, such as CHEK2, REC8, CCDC67, and PATZ1, may play a vital role in tumorigenesis in PTC [3, 15-17]. Nevertheless, the molecular mechanisms of TGSs in PTC remain unknown, which makes further study necessary for understanding the pathogenesis of PTC.

Uncoordinated-5 (Unc5) receptors, including four homologues (Unc5A-D), were expressed extensively in multiple tissues and participated in an array of cell processes [18, 19]. Intriguingly, characterized as "dependence receptors", Unc5 receptors expression is strongly suppressed in most cancers [20, 21], presumably due to pro-apoptotic and antiangiogenic properties of Unc5 signaling [22-24]. Overexpression of these receptors inhibits tumor cell anchorage-independent growth and invasion, which makes the Unc5 receptors hypothesized to be putative tumor suppressors $[25,26]$.

$U N C 5 D$, a newly added member of the Unc5 family [27], widely expressed in normal tissues, was frequently absent or attenuated in cancer cell lines and reported to be associated with multiple cancers including kidney cancer, neuroblastoma and bladder cancers [28-30]. However, to the best of our knowledge, whether UNC5D could act as a tumor suppressor gene in PTC remains unclear.

Considering this, we focused on the potential role of $U N C 5 D$ in the development of PTC (see Supplementary Figure 1). First, UNC5D expression in papillary thyroid cancer versus adjacent noncancerous tissues was investigated, and the relationship between UNC5D and clinicopathological variates was explored. Subsequently, the implication of UNC5D downregulation in PTC was analyzed by monitoring altered PTC cell behaviors following restoration of its expression in otherwise silenced cells. Data thus acquired support a tumorsuppressive function of UNC5D in PTC. We put forth that our results will lead to improved clinical pathologic classification and management of PTC patients.

\section{RESULTS}

\section{Loss or reduced expression of $U N C 5 D$ in PTC and cell lines}

We performed quantitative real-time PCR and semiquantitative reverse transcription PCR (RT-PCR) in 112 patients with primary PTC to explore the expression level of UNC5D mRNA in PTC. Quantitative real-time PCR analysis revealed that UNC5D mRNA expression was remarkably reduced in a large proportion of PTC tissues compared to adjacent noncancerous tissues. (Figure 1A).

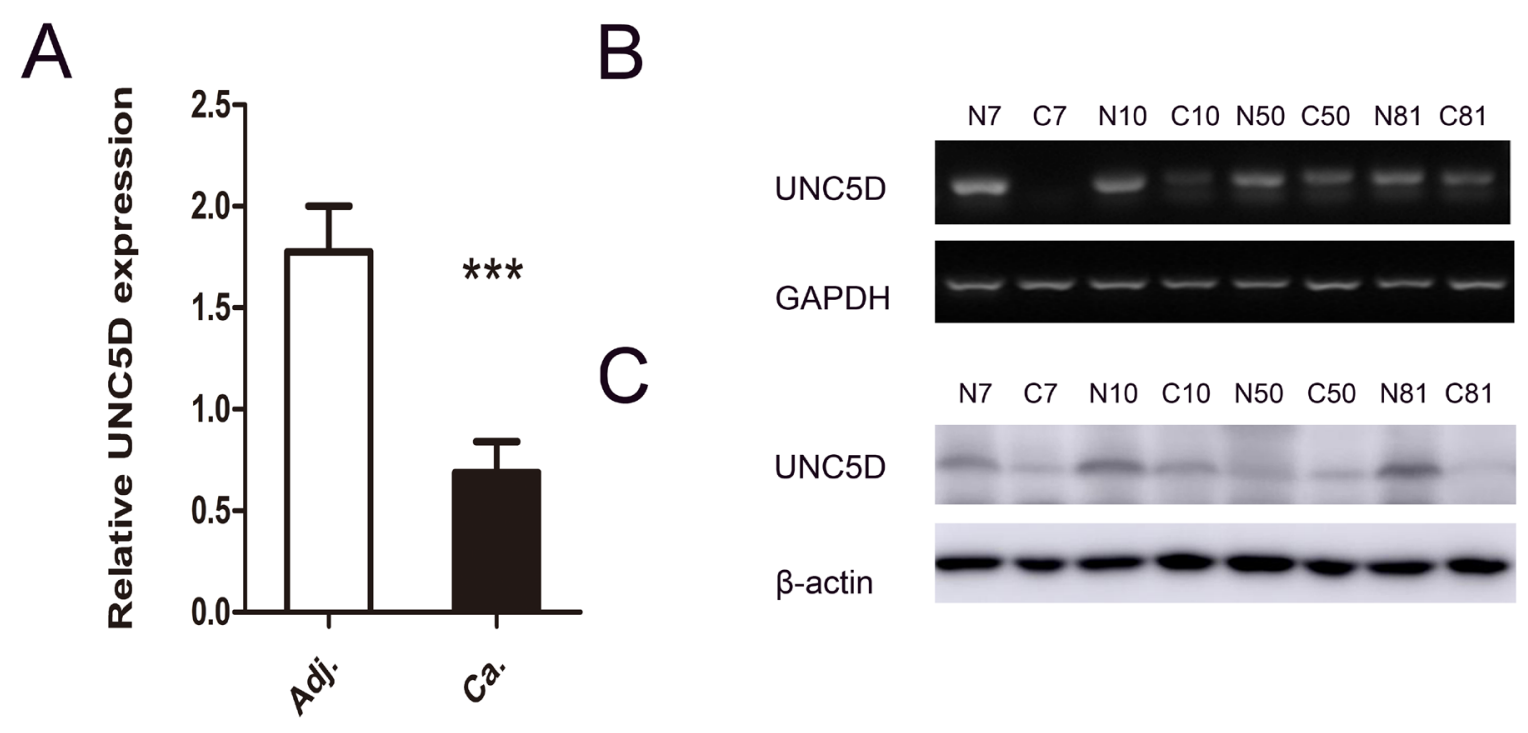

Figure 1: $\boldsymbol{U N C 5 D}$ is attenuated or silenced in PTC tissues. (A) comparison of the relative expression levels of $U N C 5 D$ in 112 paired PTC and adjacent noncancerous tissues as measured by real-time PCR. “****” indicates $P<0.01$. (B) $U N C 5 D$ mRNA expression in 4 representative pairs of PTC and adjacent noncancerous tissue as assessed by RT-PCR. (C) Western blot analysis of $U N C 5 D$ protein in PTC and adjacent normal tissues. $\mathrm{N}$, matched normal thyroid tissue; $\mathrm{C}$, cancer tissue. 
Table 1: The clinical characteristics of study subjects

\begin{tabular}{|c|c|}
\hline Characteristics & Number (\%) \\
\hline Number of patients & 112 \\
\hline Tissue samples analyzed & 224 \\
\hline \multicolumn{2}{|l|}{ Sex } \\
\hline male & 27 \\
\hline female & 85 \\
\hline \multicolumn{2}{|l|}{ Age } \\
\hline$<45 \mathrm{y}$ & 49 \\
\hline$\geq 45 y$ & 63 \\
\hline \multicolumn{2}{|l|}{ Tumor size } \\
\hline $\mathrm{T} 1$ & 63 \\
\hline $\mathrm{T} 2$ & 36 \\
\hline $\mathrm{T} 3$ & 8 \\
\hline Multifocality & $34(30 \%)$ \\
\hline Lymph node metastasis & $41(38 \%)$ \\
\hline Distant metastasis & 0 \\
\hline \multicolumn{2}{|l|}{ Tumor mutation status } \\
\hline BRAF V600E & $69(63 \%)$ \\
\hline
\end{tabular}

Tumor size were classified as tumor T status: $\mathrm{T} 1=\leq 2 \mathrm{~cm} ; \mathrm{T} 2=>2 \mathrm{~cm}$, but $<4 \mathrm{~cm}$; T3 $=\geq 4 \mathrm{~cm}$.

Such a pattern was subsequently verified using RT-PCR. As shown in Figure 1B, in a representative number of paired tissue specimens, the UNC5D mRNA expression level was weak in contrast to paired nonmalignant tissues. We further examined UNC5D protein expression in these tumors by Western blot. A similar pattern was seen with the expression of UNC5D protein (Figure 1C). Previous studies have indicated that hypermethylation of a $\mathrm{CpG}$ island in the promoter region together with loss of heterozygosity $(\mathrm{LOH})$ may contribute to the UNC5D silencing in renal cancer [28]. These results suggested that deregulated expression of UNC5D might correlate with PTC tumorigenesis and development.

\section{Down-regulation of $U N C 5 D$ expression is associated with $B R A F(V 600 E)$ mutation and aggressive behaviors of papillary thyroid cancer}

As a newly characterized tumor suppressor gene, UNC 5D was recently reported to be mutated in non-smallcell lung cancer, uterine cancer and stomach cancer in a public dataset from The Cancer Genome Atlas (TCGA); however, the TCGA analysis of PTC implied that somatic mutations targeting UNC5D are uncommon in PTC, which was consistent with data from the Catalogue of Somatic Mutations in Cancer (COSMIC) database. $B R A F^{\mathrm{V} 600 \mathrm{E}}$ was a commonly recognized hotspot mutation in PTC, and the $B R A F^{\mathrm{V} 600 \mathrm{E}}$ mutant was sequenced by Sanger sequencing in our research. As shown in Table $1, B R A F^{\mathrm{V} 600 \mathrm{E}}$ was present in 69 of 110 patients. Figure $2 \mathrm{~A}$ shows a representative electropherogram of the BRAF T1799A mutation. Compared to tumors without the $B R A F^{\mathrm{V} 600 \mathrm{E}}$ hotspot mutation, the expression of UNC5D was significantly decreased in BRAF mutated tumors (Figure 2B). Interestingly, as illustrated in Figure $2 \mathrm{C}-2 \mathrm{E}$, the $U N C 5 D$ mRNA level in patients with LNM was lower than in the non-LNM group, while the expression level of UNC5D between subgroups divided according to multifocality or tumor size displayed no significant differences. Linear regression analysis of the association between clinicopathologic features and the expression of UNC5D revealed that in addition to BRAF mutation and LNM, no correlation between the reduction in UNC5D expression and the characteristics including age, gender, tumor size and multifocality existed (Table 2). As summarized in Table 3, logistic regression analysis showed that UNC5D expression was strongly associated with the occurrence of LNM. 


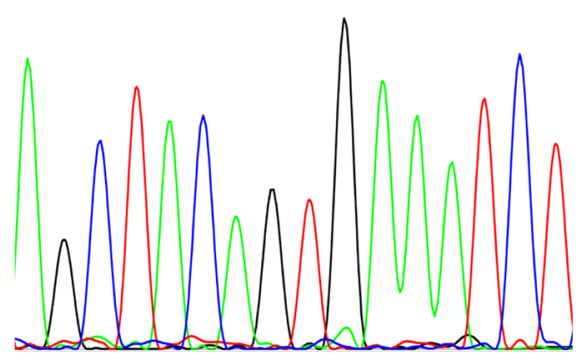

wild-type BRAF
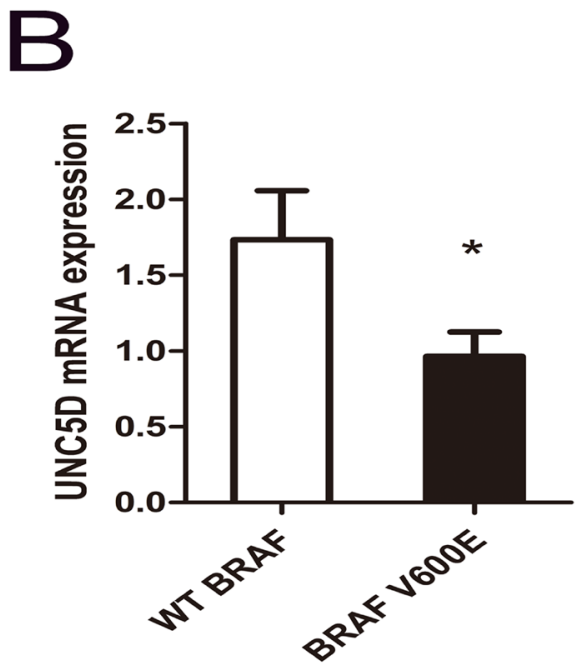

$\mathrm{D}$

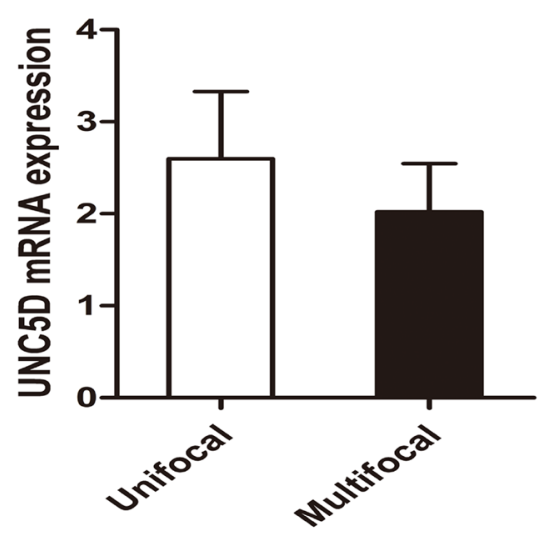

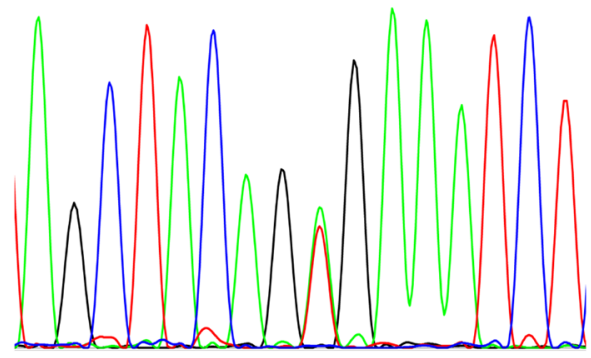

BRAF T1799A
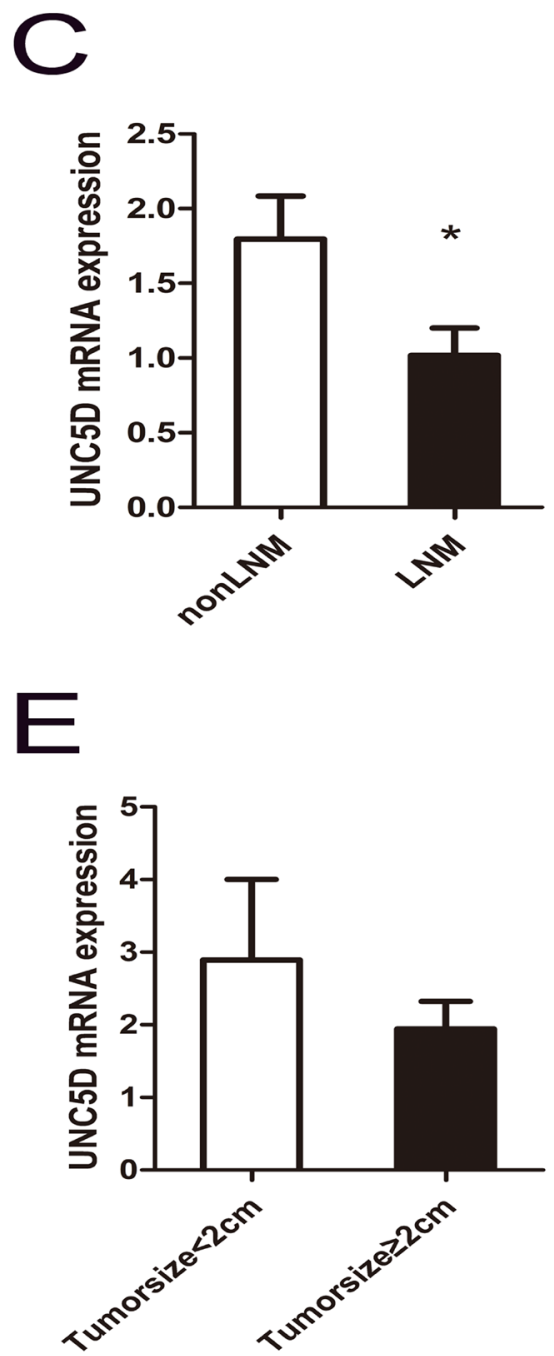

Figure 2: Aggressive tumor behaviors affected UNC5D mRNA expression levels in PTC. (A) the representative electropherogram of the hotspot mutation in the $B R A F$ gene. A case of PTC with the wild-type $B R A F$ and a case with the BRAF T1799A mutation are shown. The red rectangle indicates the nucleotide where the mutation occurs. (B-D) contrast of UNC5D mRNA expression levels between subgroups divided by with or without the $B R A F^{\mathrm{V} 600 \mathrm{E}}$ hotspot mutation (B), LNM or non-LNM(C), multifocality (D), and tumor size (E). “*”” indicates $P<0.05$. 
Table 2: Linear regression analysis of variables associated with the $U N C 5 D$ expression in PTC subjects

\begin{tabular}{|c|c|c|c|c|}
\hline \multirow[t]{2}{*}{ (A) } & \multicolumn{2}{|c|}{ Simple } & \multicolumn{2}{|c|}{ Multiple } \\
\hline & $\mathbf{r}$ & $\boldsymbol{P}$ & $\beta$ & $P$ \\
\hline Sex(female/male) & 0.078 & 0.415 & & \\
\hline Age(years) & 0.109 & 0.254 & & \\
\hline Tumor size $(\mathrm{cm})$ & 0.011 & 0.909 & & \\
\hline Multifocality & 0.016 & 0.865 & & \\
\hline$B R A F \mathrm{~V} 600 \mathrm{E}$ & 0.267 & 0.005 & 0.229 & 0.014 \\
\hline LNM & 0.202 & 0.036 & 0.233 & 0.013 \\
\hline
\end{tabular}

Table 3: Logistic regression analysis of parameters associated with LNM

\begin{tabular}{lccc}
\hline \multirow{2}{*}{ Parameters } & \multirow{2}{*}{ Category } & OR(95\% CI) & $\boldsymbol{P}$ \\
\cline { 3 - 4 } Age (year) & & $1.005(0.977-1.035)$ & 0.726 \\
Tumor size (cm) & & $1.052(0.757-1.463)$ & 0.763 \\
UNC5D & & $1.371(1.080-1.739)$ & 0.009 \\
Sex & & $2.143(0.772-5.947)$ & 0.143 \\
multifocality & Female/male & $1.310(0.568-3.022)$ & 0.527 \\
$B R A F$ status & Uni/multi-focal & $0.576(0.251-1.321)$ & 0.193 \\
\hline
\end{tabular}

\section{Restoration decreased cell proliferation and colony formation}

To uncover whether the $U N C 5 D$ acts as a tumor suppressor in PTC, the expression of UNC5D was further confirmed in two PTC-derived cancer cell lines (K1, TPC 1) by quantitative real-time PCR and RT-PCR. The results showed lower $U N C 5 D$ expression levels compared to 3 normal thyroid gland tissues (Figure 3A-3B). To determine whether $U N C 5 D$ could inhibit the proliferation or migration of thyroid cancer cells, we used a lentivirus to build the $U N C 5 D$ overexpression and negative control cell lines. The effectiveness of the transfection was confirmed by Western blotting (Figure 3C). Cell proliferation and colony formation assays were then performed to observe the function of $U N C 5 D$ in the proliferation of $\mathrm{K} 1$ and TPC-1 cells; the percentage of viable cells was detected at four time points $(0,24,48$, and 72 hours) (Figure $3 \mathrm{D})$. It was found that the overexpressed UNC5D could inhibit cell proliferation in these two PTC-derived cancer cell lines. Cell colony formation was also significantly inhibited by $U N C 5 D$ overexpression (Figure 3E). Cellcycle analysis with $U N C 5 D$ overexpressed $\mathrm{K} 1$ and TPC-1 cells both revealed an increase in G2-M phase (Figure 3F).
Based on these results, we concluded that $U N C 5 D$ might be a key mediator in the proliferation of K1 and TPC-1 cells.

\section{Overexpression of $U N C 5 D$ inhibits PTC cells migration}

We next investigated whether UNC5D could inhibit the migratory abilities of K1 and TPC-1 cells by performing the Transwell assay and scratch wound healing assay. The results observed in all UNC5Dtransfected clones, including K1 and TPC-1 cells, showed that overexpression of $U N C 5 D$ led to a nearly 2 -fold reduction in the number of cells crossing over the filter in the Transwell assay (Figure 4A-4B). By using a scratch wound-healing assay, we found that wound closure was retarded for UNC5D-overexpressing cells compared with the control cells transfected with only the empty vector (Figure 4C-4D).

\section{UNC5D inhibits tumor growth in vivo}

To further examine the effect of $U N C 5 D$ on PTC cell growth in vivo, UNC5D overexpressed and control 
A

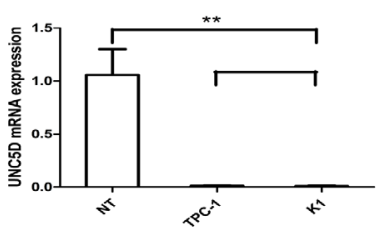

$\mathrm{C}$
B

UNC5D

GAPDH

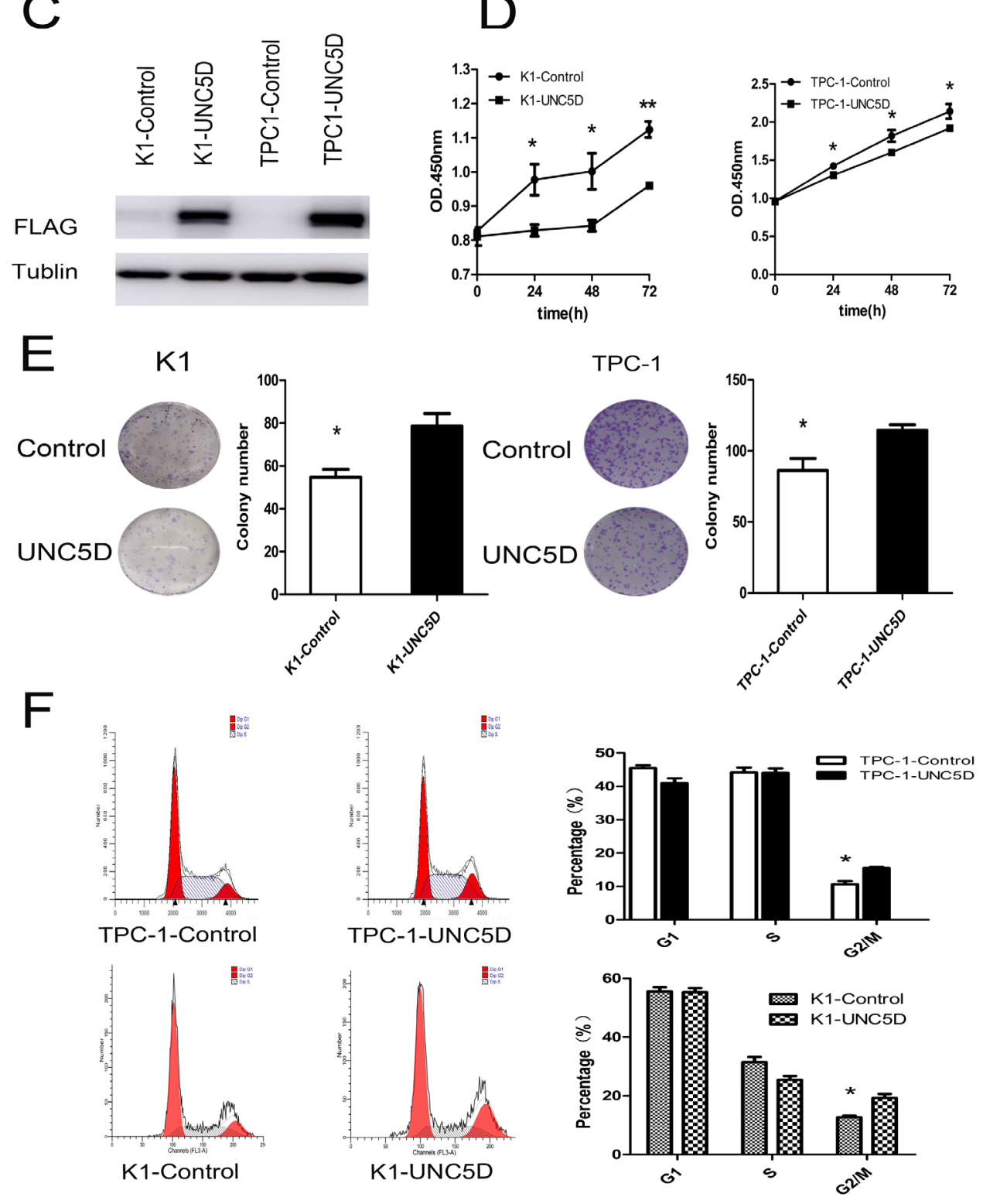

Figure 3: UNC5D inhibits PTC cell growth and cell cycle status. K1 and TPC-1 cells were infected with control/UNC5Dexpressing lentiviruses and monitored for growth using various assays. Each assay was repeated at least 3 times. (A) real time-PCR analysis of UNC5D in 2 PTC-derived cell lines (TPC-1 and K1) and 3 normal thyroid gland tissues (mean value of expression was set to 1). Means \pm SEM of triplicate samples compared to each normal control are shown. NT = three normal thyroid tissues used as a control. (B) UNC5D mRNA expression in three normal thyroid tissues and 2 thyroid cancer cell lines as assessed by RT-PCR. (C) Western blot results show the protein expression of FLAG and GAPDH. (D) cell proliferation was analyzed using CCK-8. The results are presented as absorbance (OD) at $450 \mathrm{~nm}$ for triplicate wells. “*” indicates $P<0.05$. (E) colony formation of K1 and TPC-1 cells in monolayer culture. Overexpression of UNC5D inhibited cell proliferation and the colony formation of K1 and TPC-1 cells in a monolayer culture, $P<0.05$. (F) the flow cytometric analysis of the cell cycle showed that UNC5D induced G2-M arrest in K1 and TPC-1 cells. The results quantified in the cell cycle analysis are shown as a percentage of the total number of cells. Data are expressed as the means \pm SEM of three independent experiments. “*” indicates $P<0.05$. 
A

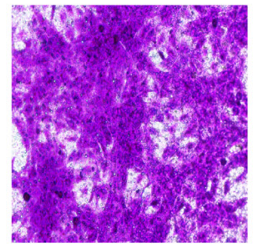

K1-Control

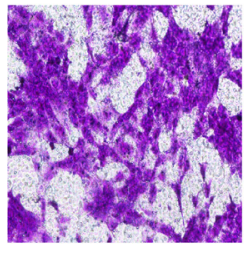

K1-UNC5D

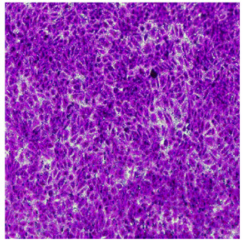

TPC-1-Control

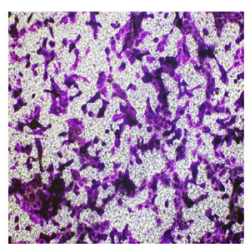

TPC-1-UNC5D
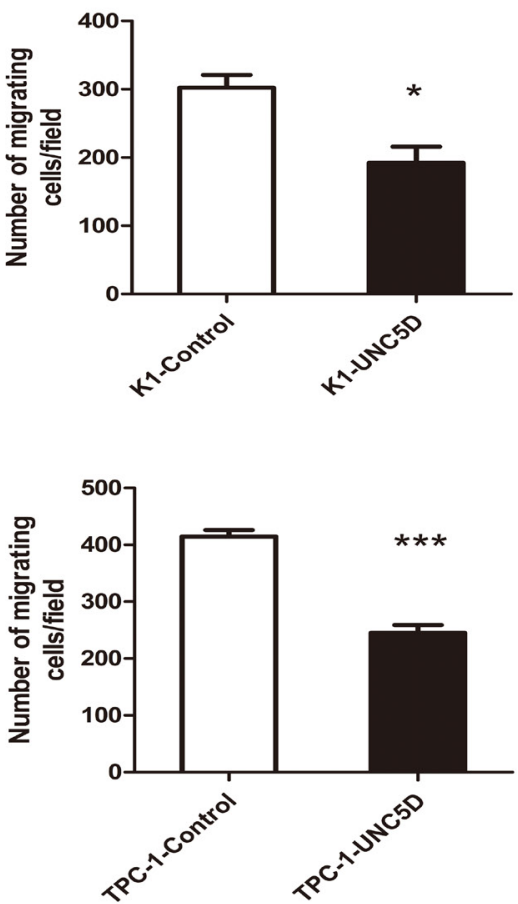

C

Oh

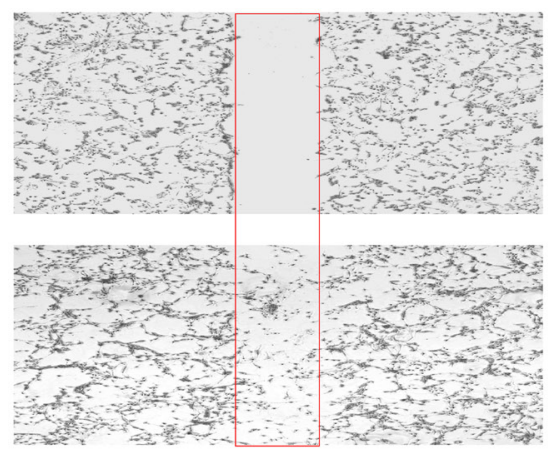

K1-Control

D

Oh

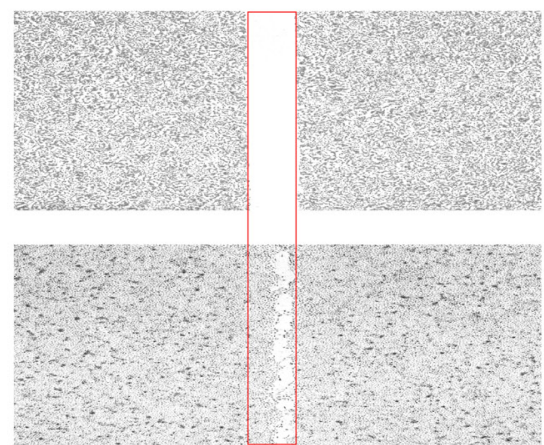

TPC-1-Control

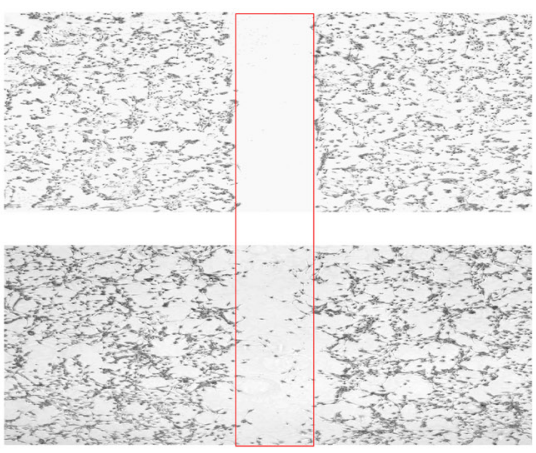

K1-UNC5D

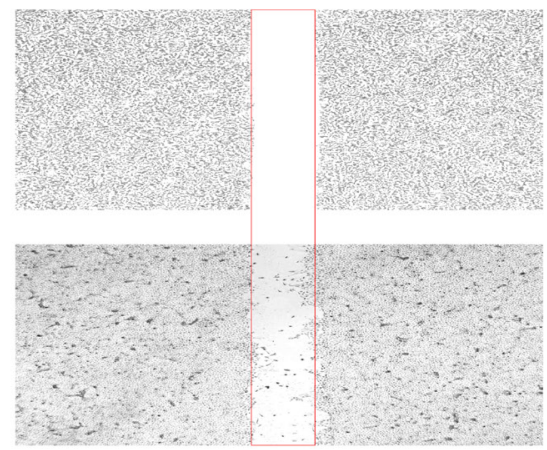

TPC-1-UNC5D

Figure 4: Effect of $U N C 5 D$ on the migration of $K 1$ and TPC-1 cells. Transwell assay was performed to determine the migration ability of K1 (A) and TPC-1 cells (B). Representative images showing cell migration in Transwell assay. The number of migration cells was counted in 6 randomly chosen fields and averaged for each of the triplicate wells. Data are expressed as the means $\pm \mathrm{SEM}$ of three independent experiments. " "*” indicates $P<0.05$, “***" indicates $P<0.01$. Representative images showing the migration of $\mathrm{K} 1$ (C) and TPC1 cells (D) in the scratch wound-healing assay at 2 points. 
K1 cells were injected subcutaneously into 4-5-week-old male nude mice. Twelve mice were divided into 2 groups (Figure 5A), and tumors were peeled from the subcutis of nude mice (Figure 5B). Consistent with in vitro results, $U N C 5 D$ significantly inhibited tumor growth in vivo through decreased tumor volume and weight in mice $(P<$ 0.05 ) (Figure 5C-5D). These results confirmed UNC5D to be a novel tumor suppressor gene for PTC.

\section{DISCUSSION}

$U N C 5 D$ is the most recently identified member of the UNC5 family. No information has been available concerning its biologic function in thyroid cancer to date. The current study, which focused on the role of UNC5D, showed for the first time that UNC5D expression was frequently reduced or lost in PTC tumors and implied its important tumor suppressor function in thyroid cancer cells.
Although the function of UNC5D is not yet completely clarified, previous studies have demonstrated that $U N C 5 D$ expression was significantly higher in favorable neuroblastomas than in unfavorable ones, and higher $U N C 5 D$ levels were correlated with longer survival time [29]. Lu et al. [28] reported that UNC5D was frequently absent or attenuated in cancer cell lines and primary renal cell carcinoma (RCC); ectopic UNC5D expression in a silenced renal cancer cell line dramatically inhibited the growth, migration and invasion of renal cancer cells. Meanwhile, genetic analysis showed that allelic imbalance significantly inhibits the $U N C 5 D$ gene in unstable bladder tumors and that $U N C 5 D$ may have important roles as a novel suppressor in bladder cancer via the $U N C 5 D / D A P K$ pathway [30]. One study reported that $U N C 5 D$ is induced during DNA damage-mediated apoptosis and is a direct transcriptional target of p53 [31]. A genome-wide associated study has identified UNC5D as one of candidate genes associated with colon cancer
A

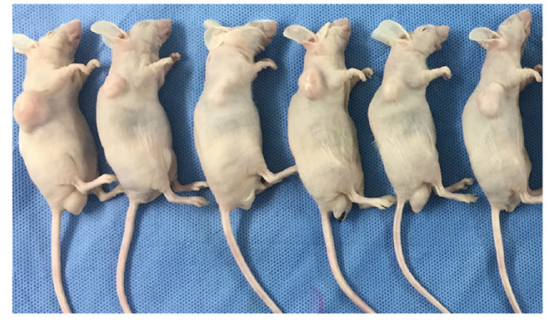

Control

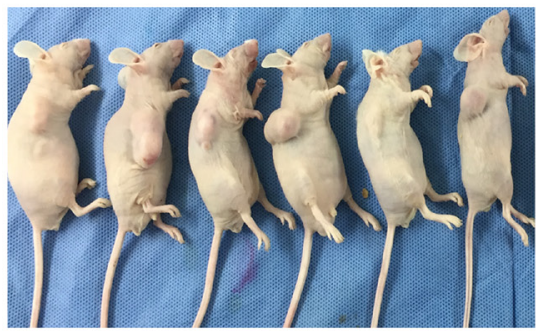

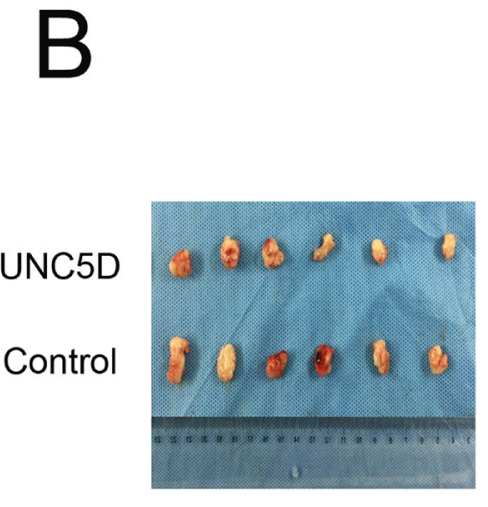
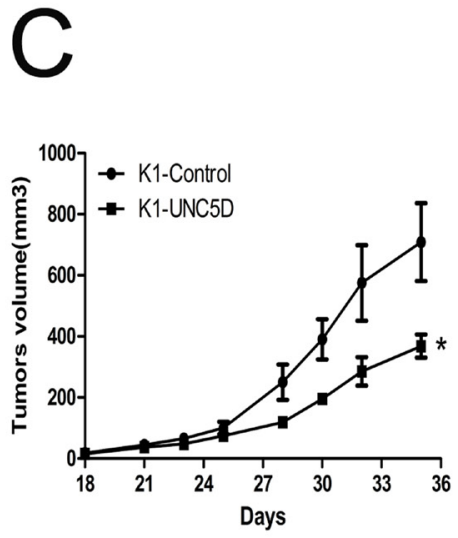
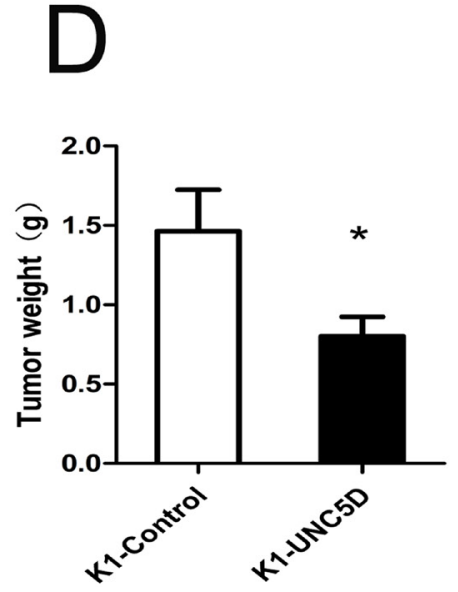

Figure 5: UNC5D inhibits PTC growth in vivo. (A) twelve 4-5-week old male BALB/c nude mice were separated into 2 groups and injected with K1-Control cells or K1-UNC5D cells. (B) solid tumors were peeled from mouse subcutaneous tissue at 35 days post-injection. (C) tumor growth curves showed the volume of xenograft tumors changed in a time-dependent manner. (D) tumor weights were measured when mice were sacrificed. The means \pm SEM are reported. "*", $P<0.05$. 
predisposition [32]. Our previous study using multi-region sequencing also identified $U N C 5 D$ as a significantly mutated gene in non-small-cell lung cancer and a late mutated event during tumorigenesis and progress [33]. However, the possible role of $U N C 5 D$ in the tumorigenesis of PTC remains unstated.

PTCs are the most common tumors of the endocrine system, although the majority of them are effectively treated with surgery and radioactive iodine; however, of note, it presents with a high rate of LNM (45\%), which results in a challenge in patients management $[34,35]$. Therefore, it becomes urgent to expand our understanding of the pathogenic mechanisms of tumorigenesis and identify effective therapeutic targets for these refractory patients. Here, our study elicited that the expression level of $U N C 5 D$ in PTC tumors was dramatically lower compared to normal adjacent tissues. Furthermore, a significant decrease in the UNC5D mRNA expression level was observed in PTC patients with a $B R A F^{\mathrm{V} 600 \mathrm{E}}$ hotspot or LNM. Correlation analysis indicated a relatively good relationship between the expression level of $U N C 5 D$ and the aggressive clinical factors, including $B R A F$ mutation and LNM. The BRAF V600E mutation is common in PTC, and patients with PTC harboring the $B R A F^{V 600 E}$ mutation appear to display more aggressive clinical behavior [36]. LNM may be associated with poor prognosis; however, the mechanism of LNM remains unclear [37].

To assess the biological significance of UNC5D in thyroid cancer pathogenesis, we used a lentiviral-mediated $U N C 5 D$ overexpression vector to effectively upregulate $U N C 5 D$ expression in the PTC cell lines K1 and TPC1 . We found that overexpression of UNC5D significantly decreased the cellular capacity to proliferate, suggesting a tumor suppressor role of $U N C 5 D$ in opposing the malignant transformation of PTC. Additionally, UNC5D overexpression also displayed a profound inhibitory effect on cell mobility, leading to reduced migratory activity in PTC cells. Cell cycle analysis in our study showed that overexpressed UNC5D could induce G2-M cell-cycle arrest in thyroid cancer cells, which was similar to the results that have been reported in primary renal cancer cells [28]. Cell cycle regulation is a common process crucial to the tumor formation [38]. In addition, one Netrin-1 receptor $D C C$ induced G2-M arrest by inhibition of $C d k 1$ [39]. Most recently, $U N C 5 B$ was reported to inhibit proliferation and migration by inhibiting cell cycle progression at the G2-M phase in bladder cancer cells [40]. Further studies will test whether cell-cycle arrest is a common event initiated by UNC5 receptors.

The finding of the present study of the association between the down-regulation of UNC5D and the BRAF V600E mutation in PTC was intriguing. It implicated that there existed a potential repellence between the activation of $B R A F$ and $U N C 5 D$ expression, and also suggested that the former might participate in the negative regulation of the latter, which indicated that $U N C 5 D$ might be a new target gene of $B R A F^{V 600 E}$ in PTC. These findings might expand the genetic repertoire and provide a potential therapeutic target for thyroid cancer. Logistic regression analysis demonstrated a comparatively strong interrelation between $U N C 5 D$ expression with the occurrence of LNM, which suggested that the potential role of UNC5D in the LNM of PTC and the specific mechanism requires clarification. Nevertheless, the clinicopathological data and the cellular functional data in the present study are sufficient to establish that $U N C 5 D$ is a novel tumor suppressor gene in thyroid cancer and is associated with tumor aggressiveness.

In summary, this is the first study that highlighted the tumor suppressor potential of UNC5D in PTC, which may serve as a potential diagnostic and therapeutic target for PTC intervention. It also extends our current understanding of the mechanism of UNC5D in the pathogenesis of PTC.

\section{MATERIALS AND METHODS}

\section{Subjects}

A total of 112 patients with pathologically confirmed PTC were enrolled at the First Affiliated Hospital of Bengbu Medical College and Shanghai Ruijin Hospital between October 2013 and December 2014. PTC and adjacent normal thyroid tissue samples were obtained and immediately stored at $-80^{\circ} \mathrm{C}$. Histopathologic diagnoses were established according to the World Health Organization (WHO) classification and reviewed by two independent pathologists. This study was approved by the Research Ethics Committee of Shanghai Ninth People's Hospital. Demographic information for each patient is described in Supplementary Table 1.

\section{Detection of $B R A F$ mutation in PTC}

The BRAF T1799A mutation was analyzed using genomic DNA isolated from 112 cases of primary PTC tissue samples that were available for DNA isolation. Genomic DNA was extracted using a DNeasy Blood \& Tissue Kit (QIAGEN, Valencia, CA, USA), according to the manufacturer's instructions. As DNA quality was suboptimal for subsequent PCR and sequencing in 2 samples, we excluded them and proceeded with the detection of $B R A F$ gene mutation by direct genomic DNA sequencing analysis in 110 patients. The primers used for PCR were (5'-3'):TCTGCAGCATCTTCATTCCA (forward) and GCCTCAATTCTTACCATCCACA (reverse). After confirmation of the efficiency and quality of the amplification PCR by running the PCR products on a $2.0 \%$ agarose gel, the PCR products were purified and sequenced by BioSune Company (Shanghai, China). 


\section{Cell culture}

The human PTC cell lines TPC-1 and K1 were kind gifts from the Key Laboratory for Endocrine and Metabolic Diseases of the Chinese Health Ministry (Shanghai, China) [41]. TPC-1 cells were cultured in RPMI 1640 medium supplemented with 10\% FBS (Gibco). K1 cells were cultured in DMEM (Gibco), MCDB (Sigma, Saint Louis, Missouri, USA), and F 12 (Gibco) (2:1:1) medium supplemented with 10\% FBS (Gibco). These cell lines were maintained in a 5\% CO2humidified atmosphere at $37^{\circ} \mathrm{C}$. All cell cultures were routinely passaged at $90-95 \%$ confluency.

\section{RNA extraction, reverse transcriptase PCR and real-time PCR}

Total RNA was isolated from frozen stored tissue specimens and cells using Trizol reagent (Invitrogen) according to the manufacturer's instructions and then treated with DNase I at room temperature for $10 \mathrm{~min}$ to degrade possible contaminating genomic DNA. cDNA was made from $1 \mu \mathrm{g}$ RNA templates using reverse transcriptase and oligo (dT) primer (Takara). Quantitative real-time PCR for a series of genes was performed in triplicate using the SYBR Green and ABI ViiA TM 7 RealTime PCR System as previously described [42]. Data were analyzed and presented relative to the expression of the $G A P D H$ housekeeping gene. The primer sequences used for real-time PCR are as follows: UNC5D: forward primer, 5'-GGGACACTGCCTCATTTCAT-3', reverse primer, 5'CATGGAAGTCCTCCACCTGT-3'; GAPDH: forward primer, 5'- GAAGGTGAAGGTCGGAGTCA-3', and reverse primer, 5'- ATCTCGCTCCTGGAAGATGG-3'.

\section{Construction of lentiviral vectors and transduction}

The full-length UNC5D-3FLAG cDNA clones were obtained from Generay (Shanghai, China). To construct TPC-1 and K1 cells stably expressing 3FLAG-tagged $U N C 5 D$, a lentivirus-mediated infection system was used. For overexpression of $U N C 5 D$, DNA encoding $3 F L A G-$ tagged $U N C 5 D$ was inserted into the multi-cloning site of the pLenti vector. The sequences of the primers were as follows: forward primer, 5'-CGGGATCCCGATGGG GAGAGCGGCGGC-3' and reverse primer, 5'-GCTCT AGAGCTTACTTGTCGTCATCGTCT-3'. Lentiviruses were subsequently produced by transiently co-transfecting HEK-293 cells with the pLenti-CMV-EGFP-PURO vector and the packaging vectors $\mathrm{pLP} 1, \mathrm{pLP} 2$, and $\mathrm{plp} /$ vsvg pMD2.G, using Lipofectamine 2000 (Invitrogen). At $48 \mathrm{~h}$ after transfection, media containing retroviruses were collected, filtered with $0.45 \mu \mathrm{m}$ filters and used to infect cells in the presence of $8 \mu \mathrm{g} / \mathrm{ml}$ polybrene (Sigma). Infected cells were selected using $2 \mathrm{mg} / \mathrm{ml}$ puromycin
(Sigma) and further maintained in growth medium. Overexpression of 3FLAG-tagged UNC5D was confirmed by real-time PCR and Western blot analysis.

\section{Western blotting}

Cell pellets or thyroid tissue samples were lysed in sample buffer as previously described [43]. Total cellular protein concentrations were determined using a BCA assay kit (Beyotime Biotechnology, China). An equal amount of protein of approximately $30 \mu \mathrm{g}$ was separated by sodium dodecyl sulfate-polyacrylamide gel electrophoresis (SDS-PAGE) and transferred onto a polyvinylidene fluoride (PVDF) membrane. They were then incubated with primary antibodies including anti-GAPDH (Cell Signal Technology), anti-Flag (Sigma-Aldrich), and antiUNC5D (Santa Cruz) and subsequently with horseradish peroxidase-linked secondary antibodies. The signal was detected using enhanced chemiluminescence (Amersham Imager 600, USA).

\section{Cell proliferation}

Cell proliferation was measured by using Cell Counting Kit-8 (CCK-8), according to the manufacturer's instructions. Each condition was repeated at least 3 times. Absorbance at $450 \mathrm{~nm}$ was measured on a microplate reader at the designated time points after treatment.

\section{Cell-cycle analysis}

TPC-1 and K1 cells infected with lentiviruses encoding $U N C 5 D$, or EGFP alone, were harvested and fixed with ice-cold $70 \%$ ethanol. After washing with PBS, the cell pellet was resuspended in PBS containing $10 \mathrm{mg} / \mathrm{mL}$ propidium iodide (PI, Sigma Aldrich) and 500 $\mathrm{mg} / \mathrm{mL}$ RNase A (Sigma-Aldrich) and incubated at $37^{\circ} \mathrm{C}$ for 30 minutes. Samples were then analyzed on a BD FACSCalibur.

\section{Colony formation assay}

Five hundred infected TPC-1 and K1 cells were plated in a 6-well plate and cultured in medium for 10 days. Colonies were fixed with precooled methanol, and colonies were then stained with $0.5 \%(\mathrm{w} / \mathrm{v})$ crystal violet for 30 minutes at room temperature, washed with PBS, photographed and counted.

\section{Wound-healing assay}

Cell motility was determined by measuring the movement of cells close to an artificial wound. Cells were wounded with a $200 \mu \mathrm{L}$ pipette tip, washed with PBS, and incubated in RPMI 1640 medium without FBS. The distances removed by cells were monitored by microscopy at the indicated time points. 


\section{Transwell assay}

For the migration assay, infected cells were seeded into the upper chamber of a Transwell with a fibronectincoated filter (8-mm pore size, Corning Life Sciences). The bottom chamber contained medium containing $10 \%$ FBS. After a 20-hour incubation, cells adherent to the upper surface of the filter were removed using a cotton swab, and those attached to the bottom of the membranes were stained with crystal violet following fixation with methanol.

\section{Tumor xenografts model}

Twelve BALB/c nude mice (4-5 weeks old, male) were randomly assigned to 2 groups. We injected infected K1-Control or K1-UNC5D cells $\left(1 \times 10^{7}\right)$ subcutaneously into the right flank of BALB/c nude mice and measured the tumor dimensions by caliper every 2-3 days. The tumor volumes were calculated using the following formula: [length $(\mathrm{mm}) \times$ width $(\mathrm{mm}) \times$ width $(\mathrm{mm}) \times 0.5]$. Upon termination, tumors were harvested and weighed. All experimental protocols conducted on the mice were performed in accordance with National Institutes of Health (NIH) guidelines and were approved by the Shanghai Jiaotong University Animal Care and Use Committee.

\section{Statistical analysis}

All in vitro experiments were done in triplicate. Quantitative data are presented as individual data plots or as the means \pm SEM of the 3 independent experiments with triplicate determinations. Statistically significant differences were determined by the 2-tailed unpaired Student's t-test. The correlations between gene expression and potential causative variables were evaluated with the Pearson or Spearman correlation. Logistic regression was used for the univariate analysis. These analyses were performed using SPSS 13.0 software (SPSS, Chicago, IL). $P$ values $<0.05$ were considered statistically significant.

\section{Abbreviations}

PTC, papillary thyroid cancer; TSG, tumor suppressor genes; $U N C 5 D$, unc-5 netrin receptor D; LNM, lymph node metastasis.

\section{Author contributions}

H.D.S. and B.H. conceived and designed the project. M.M.Z. and F.S. contributed to the project management and the cell functional study, Y.L., R.J.Z. and Y.F. carried the animal experiment. M.M.Z. and L.L.Z. took part in the statistical analysis. B.C, Y.R.M. and X.P.Y. took part in the collection of clinical samples, extracted DNA and sample quality control. M.M.Z. and B.H. wrote the manuscript.

\section{ACKNOWLEDGMENTS}

The authors gratefully acknowledge all the participants for their support in this research work.

\section{CONFLICTS OF INTEREST}

The authors have declared that no conflict of interest exists that could be perceived as prejudicing the impartiality of the research reported.

\section{FUNDING}

This work was supported by grants from National Natural Science Foundation of China (Grant number: $81500602,81430019,81370888,81670717,81472177$ and 31571296).

\section{REFERENCES}

1. Siegel RL, Miller KD, Jemal A. Cancer Statistics, 2017. CA Cancer J Clin. 2017; 67:7-30.

2. Schneider DF, Chen H. New developments in the diagnosis and treatment of thyroid cancer. CA Cancer J Clin. 2013; 63:374-394.

3. Cancer Genome Atlas Network. Integrated genomic characterization of papillary thyroid carcinoma. Cell. 2014; 159:676-690.

4. Hay ID, Thompson GB, Grant CS, Bergstralh EJ, Dvorak CE, Gorman CA, Maurer MS, McIver B, Mullan BP, Oberg AL, Powell CC, van Heerden JA, Goellner JR. Papillary thyroid carcinoma managed at the Mayo Clinic during six decades (1940-1999): temporal trends in initial therapy and long-term outcome in 2444 consecutively treated patients. World J Surg. 2002; 26:879-885.

5. Kunavisarut T. Diagnostic biomarkers of differentiated thyroid cancer. Endocrine. 2013; 44:616-622.

6. Siironen P, Louhimo J, Nordling S, Ristimaki A, Maenpaa H, Haapiainen R, Haglund C. Prognostic factors in papillary thyroid cancer: an evaluation of 601 consecutive patients. Tumour Biol. 2005; 26:57-64.

7. Siraj AK, Masoodi T, Bu R, Beg S, Al-Sobhi SS, Al-Dayel F, Al-Dawish M, Alkuraya FS, Al-Kuraya KS. Genomic Profiling of Thyroid Cancer Reveals a Role for Thyroglobulin in Metastasis. Am J Hum Genet. 2016; 98:1170-1180.

8. Xing M. Molecular pathogenesis and mechanisms of thyroid cancer. Nat Rev Cancer. 2013; 13:184-199.

9. Xing M. BRAF mutation in papillary thyroid cancer: pathogenic role, molecular bases, and clinical implications. Endocr Rev. 2007; 28:742-762. 
10. Lemoine NR, Mayall ES, Wyllie FS, Farr CJ, Hughes D, Padua RA, Thurston V, Williams ED, Wynfordthomas D. Activated ras oncogenes in human thyroid cancers. Cancer Res. 1988; 48:4459.

11. Cohen Y, Xing M, Mambo E, Guo Z, Wu G, Trink B, Beller U, Westra WH, Ladenson PW, Sidransky D. BRAF mutation in papillary thyroid carcinoma. J Natl Cancer Inst. 2003; 95:625

12. Kimura ET, Nikiforova MN, Zhu Z, Knauf JA, Nikiforov YE, Fagin JA. High Prevalence of BRAF Mutations in Thyroid Cancer Genetic Evidence for Constitutive Activation of the RET/PTC-RAS-BRAF Signaling Pathway in Papillary Thyroid Carcinoma. Cancer Res. 2003; 63:1454.

13. Grieco M, Santoro M, Berlingieri MT, Melillo RM, Donghi R, Bongarzone I, Pierotti MA, Della PG, Fusco A, Vecchio G. PTC is a novel rearranged form of the RET protooncogene and frequently detected in vivo in human thyroid papillary carcinomas. Cell. 1990; 60:557-563.

14. Pierotti MA, Bongarzone I, Borrello MG, Mariani C, Miranda C, Sozzi G, Greco A. Rearrangements of TRK proto-oncogene in papillary thyroid carcinomas. J Endocrinol Invest. 1995; 18:130-133.

15. Yin DT, Xu J, Lei Xing M, Li H, Wang Y, Liu Z, Zhou Y, Xing M. Characterization of the novel tumor-suppressor gene CCDC67 in papillary thyroid carcinoma. Oncotarget. 2015; 7:5830. https://doi.org/10.18632/oncotarget.6709.

16. Chiappetta G, Valentino T, Vitiello M, Pasquinelli R, Monaco M, Palma G, Sepe R, Luciano A, Pallante P, Palmieri D, Aiello C, Rea D, Losito SN, et al. PATZ1 acts as a tumor suppressor in thyroid cancer via targeting p53-dependent genes involved in EMT and cell migration. Oncotarget. 2015; 6:5310. https://doi.org/10.18632/oncotarget.2776.

17. Liu D, Shen X, Zhu G, Xing M. REC8is a novel tumor suppressor gene epigenetically robustly targeted by the PI3K pathway in thyroid cancer. Oncotarget. 2015; 6:39211-39224. https://doi.org/10.18632/oncotarget.5391.

18. Moore SW, Tessier-Lavigne M, Kennedy TE. Netrins and their receptors. Adv Exp Med Biol. 2007; 621:17.

19. Jackson VA, Mehmood S, Chavent M, Roversi P, Carrasquero M, del Toro D, Seyit-Bremer G, Ranaivoson FM, Comoletti D, Sansom MS, Robinson CV, Klein R, Seiradake E. Super-complexes of adhesion GPCRs and neural guidance receptors. Nat Commun. 2016; 7:11184.

20. Thiebault K, Mazelin L, Pays L, Llambi F, Joly MO, Scoazec JY, Saurin JC, Romeo G, Mehlen P. The netrin-1 receptors $\mathrm{UNC5H}$ are putative tumor suppressors controlling cell death commitment. Proc Natl Acad Sci U S A. $2003 ; 100: 4173-4178$.

21. Goldschneider D, Mehlen P. Dependence receptors: a new paradigm in cell signaling and cancer therapy. Oncogene. 2010; 29:1865-1882.

22. Koch AW, Mathivet T, Larrivee B, Tong RK, Kowalski J, Pibouin-Fragner L, Bouvree K, Stawicki S, Nicholes
K, Rathore N, Scales SJ, Luis E, del Toro R, et al. Robo4 maintains vessel integrity and inhibits angiogenesis by interacting with UNC5B. Dev Cell. 2011; 20:33-46.

23. Lu X, Le Noble F, Yuan L, Jiang Q, De Lafarge B, Sugiyama D, Bréant C, Claes F, De Smet F, Thomas JL, Autiero M, Carmeliet P, Tessier-Lavigne M, et al. The netrin receptor UNC5B mediates guidance events controlling morphogenesis of the vascular system. Nature. 2004; 432:179-186.

24. Mehlen P, Goldschneider D. Dependence receptors DCC and UNC5H: the role of apoptosis in the control of tumorigenesis. J Soc Biol. 2005; 199:211-218.

25. Hibi K, Mizukami H, Shirahata A, Goto T, Sakata M, Sanada Y. Aberrant methylation of the netrin-1 receptor genes UNC5C and DCC detected in advanced colorectal cancer. World J Surg. 2009; 33:1053-1057.

26. Bernet A, Mazelin L, Coissieux MM, Gadot N, Ackerman SL, Scoazec JY, Mehlen P. Inactivation of the UNC5C Netrin-1 receptor is associated with tumor progression in colorectal malignancies. Gastroenterology. 2007; 133:1840-1848.

27. Engelkamp D. Cloning of three mouse Unc5 genes and their expression patterns at mid-gestation. Mech Dev. 2002; 118:191-197.

28. Lu D, Dong D, Zhou Y, Lu M, Pang XW, Li Y, Tian XJ, Zhang Y, Zhang J. The tumor-suppressive function of UNC5D and its repressed expression in renal cell carcinoma. Clin Cancer Res. 2013; 19:2883-2892.

29. Zhu Y, Li Y, Haraguchi S, Yu M, Ohira M, Ozaki T, Nakagawa A, Ushijima T, Isogai E, Koseki H, Nakamura $\mathrm{Y}$, Kong $\mathrm{C}$, Mehlen $\mathrm{P}$, et al. Dependence receptor UNC5D mediates nerve growth factor depletioninduced neuroblastoma regression. J Clin Invest. 2013; 123:2935-2947.

30. Zhu Y, Yu M, Chen Y, Wang Y, Wang J, Yang C, Bi J. Down-regulation of UNC5D in bladder cancer: UNC5D as a possible mediator of cisplatin induced apoptosis in bladder cancer cells. J Urol. 2014; 192:575-582.

31. Wang H, Ozaki T, Shamim Hossain M, Nakamura Y, Kamijo T, Xue X, Nakagawara A. A newly identified dependence receptor UNC5H4 is induced during DNA damage-mediated apoptosis and transcriptional target of tumor suppressor p53. Biochem Biophys Res Commun. 2008; 370:594-598.

32. Liu P, Lu Y, Liu H, Wen W, Jia D, Wang Y, You M. Genome-wide association and fine mapping of genetic loci predisposing to colon carcinogenesis in mice. Mol Cancer Res. 2012; 10:66.

33. Zhang LL, Kan M, Zhang MM, Yu SS, Xie HJ, Gu ZH, Wang HN, Zhao SX, Zhou GB, Song HD, Zheng CX. Multiregion sequencing reveals the intratumor heterogeneity of driver mutations in TP53-driven non-small cell lung cancer. Int J Cancer. 2017; 140:103-108. 
34. Popadich A, Levin O, Lee JC, Smooke-Praw S, Ro K, Fazel M, Arora A, Tolley NS, Palazzo F, Learoyd DL, Sidhu S, Delbridge L, Sywak M, et al. A multicenter cohort study of total thyroidectomy and routine central lymph node dissection for cN0 papillary thyroid cancer. Surgery. 2011; 150:1048-1057.

35. Qiu W, Yang Z, Fan Y, Zheng Q. ZNRF3 is downregulated in papillary thyroid carcinoma and suppresses the proliferation and invasion of papillary thyroid cancer cells. Tumour Biol. 2016; 37:12665-12672.

36. Nucera C, Lawler J, Parangi S. BRAF(V600E) and microenvironment in thyroid cancer: a functional link to drive cancer progression. Cancer Res. 2011; 71:2417-2422.

37. Kurtulmus N, Ertas B, Saglican Y, Kaya H, Ince U, Duren M. BRAFV600E Mutation: Has It a Role in Cervical Lymph Node Metastasis of Papillary Thyroid Cancer? Eur Thyroid J. 2016; 5:195-200.

38. Tsaniras SC, Kanellakis N, Symeonidou IE, Nikolopoulou P, Lygerou Z, Taraviras S. Licensing of DNA replication, cancer, pluripotency and differentiation: An interlinked world? Semin Cell Dev Biol. 2014; 30:174.
39. Chen YQ, Hsieh JT, Yao F, Fang B, Pong RC, Cipriano $\mathrm{SC}$, Krepulat F. Induction of apoptosis and G2/M cell cycle arrest by DCC. Oncogene. 1999; 18:2747-2754.

40. Kong C, Bo Z, Piao C, Zhe Z, Zhu Y, Li Q. Overexpression of UNC5B in bladder cancer cells inhibits proliferation and reduces the volume of transplantation tumors in nude mice. BMC Cancer. 2016; 16:892.

41. Xia S, Wang C, Ni X, Ni Z, Dong Y, Zhan W. NONHSAT076754 aids ultrasonography in predicting lymph node metastasis and promotes migration and invasion of papillary thyroid cancer cells. Oncotarget. 2017; 8:2293-2306. https://doi.org/10.18632/oncotarget.13725.

42. Zhan M, Chen G, Pan CM, Gu ZH, Zhao SX, Liu W, Wang HN, Ye XP, Xie HJ, Yu SS, Liang J, Gao GQ, Yuan $\mathrm{GY}$, et al. Genome-wide association study identifies a novel susceptibility gene for serum TSH levels in Chinese populations. Hum Mol Genet. 2014; 23:5505-5517.

43. Ma QY, Zuo CL, Ma JH, Zhang XN, Ru Y, Li P, Pan CM, Liu Z, Cao HM, Chen MD, Song HD. Glucocorticoid up-regulates mimecan expression in corticotroph cells. Mol Cell Endocrinol. 2010; 321:239-244. 